\title{
ABSTRACT \\ ATTITUDES OF SAUDI EFL STUDENTS TOWARD \\ AMERICAN AND BRITISH ACCENTS
}

This thesis examined the attitudes of 63 Saudi female EFL students in Saudi Arabia toward British and American accents. The results showed a preference for British and female speakers, particularly in terms of status, despite participants' inability to distinguish British and American accents consciously. This suggests that conscious ability to distinguish speakers' dialects and identify their nationalities is not a necessary precondition to having different (unconscious) perceptions of those speakers. The bases of the unconscious perceptions found in this thesis remain a mystery.

Eiman Nassar Alenezy

December 2015 

ATTITUDES OF SAUDI EFL STUDENTS TOWARD AMERICAN AND BRITISH ACCENTS

by

Eiman Nassar Alenezy

\author{
A thesis \\ submitted in partial \\ fulfillment of the requirements for the degree of \\ Master of Arts in Linguistics \\ in the College of Arts and Humanities \\ California State University, Fresno \\ December 2015
}




\section{APPROVED}

For the Department of Linguistics:

We, the undersigned, certify that the thesis of the following student meets the required standards of scholarship, format, and style of the university and the student's graduate degree program for the awarding of the master's degree.

Eiman Nassar Alenezy

Thesis Author

$\overline{\text { Michael Shepherd (Chair) }}$ Linguistics

\begin{tabular}{ll}
\hline Sean Fulop & Linguistics
\end{tabular}

Chris Golston

Linguistics

For the University Graduate Committee:

Dean, Division of Graduate Studies 


\section{AUTHORIZATION FOR REPRODUCTION}

\section{OF MASTER'S THESIS}

$\mathrm{X} \quad$ I grant permission for the reproduction of this thesis in part or in its entirety without further authorization from me, on the condition that the person or agency requesting reproduction absorbs the cost and provides proper acknowledgment of authorship.

Permission to reproduce this thesis in part or in its entirety must be obtained from me.

Signature of thesis author: 


\section{ACKNOWLEDGMENTS}

I would like to express my gratitude to the chair of my thesis committee, Dr. Michael Shepherd, for his supervision and guidance. It was an honor to have such a persistent and supportive professor to help and guide me through my graduate study. His guidance empowered my academic achievement and opened a new horizon for me in the field of sociolinguistics. I chose to do my Master's thesis in sociolinguistics and to pursue my PHD in this field as a result of this inspiration.

I would also like to express my appreciation for Dr. Sean Fulop, my academic advisor, and Dr. Chris Golston, both thesis committee members, for their supervision, as well as their intellectual input and feedback. Essentially, I must thank all faculty members of the Linguistics department at California State University at Fresno from whom I have learned and acquired invaluable knowledge and experience.

Finally, I would like to take the chance to express my great appreciation for my husband and my mom for their endless encouragement and support during this unique stage of my life. Also, I am grateful to my government for their financial support and for giving me the chance to complete my study in California State University at Fresno. 


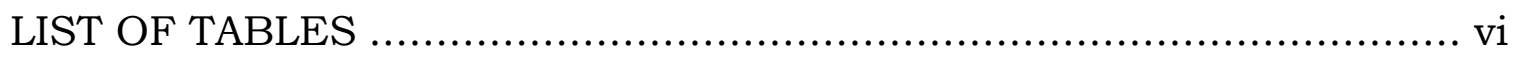

LIST OF FIGURES .......................................................................

CHAPTER 1: INTRODUCTION .............................................. 1

CHAPTER 2: LITERATURE REVIEW .......................................... 2

The Matched Guise Technique and Verbal Guise Technique............ 2

Language Attitudes of Non-Native Speakers ................................ 3

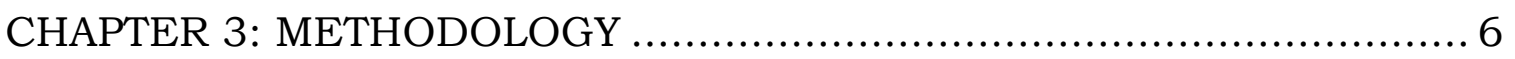

Preliminary Study - Method.................................................. 6

Preliminary Study - Results............................................... 8

Main Study - Method........................................................... 8

Main Study - Results..................................................... 10

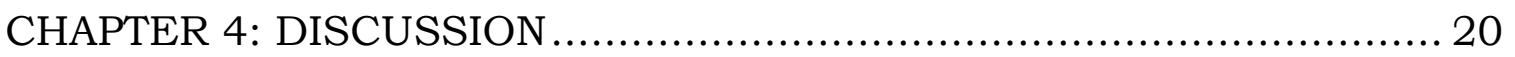

CHAPTER 5: LIMITATIONS AND CONCLUSION................................ 21

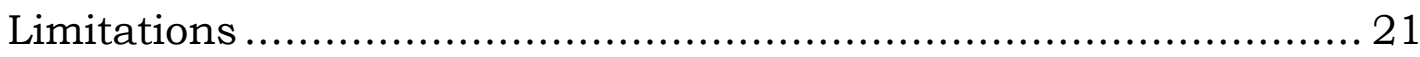

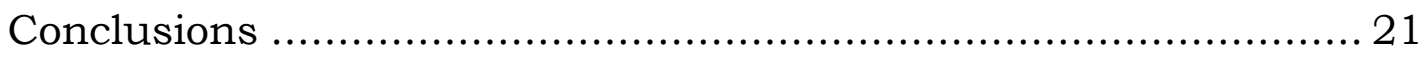

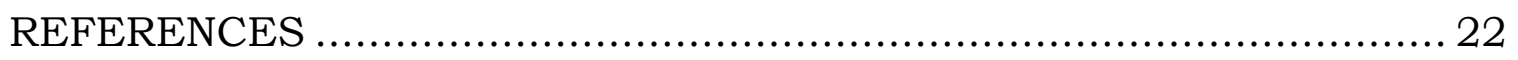

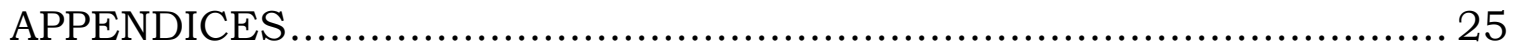

APPENDIX A: TEXT OF THE PASSAGE READ BY SPEAKERS.............. 26

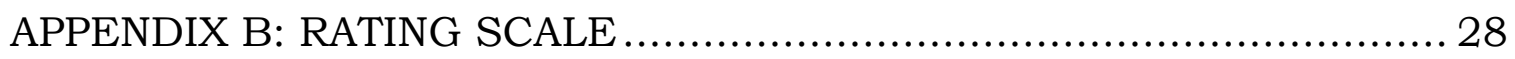




\section{LIST OF TABLES}

Page

Table 1 Summary of Statistical Significant p-Values ........................... 12 


\section{LIST OF FIGURES}

Page

Figure 1. Mean attractive ....................................................... 13

Figure 2. Mean confident....................................................... 14

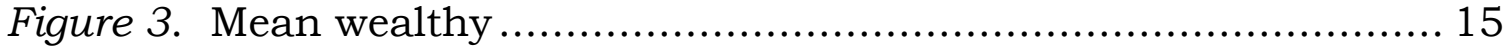

Figure 4. Mean educated ........................................................... 16

Figure 5. Mean polite ............................................................ 17

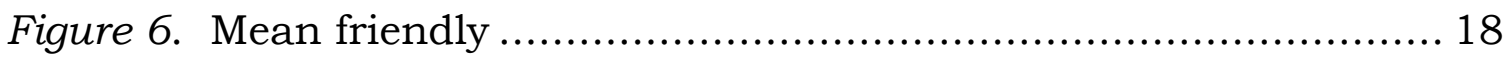

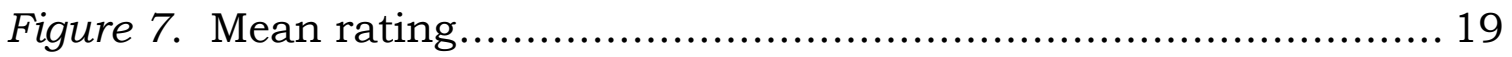




\section{CHAPTER 1: INTRODUCTION}

One of the main concerns of English as a Foreign Language (EFL) student is accent: which accent - typically American or British - is easier to understand, which is considered more "standard," and ultimately which should EFL students try to model? This study examined the attitudes of Saudi female EFL students in the English Department at a Saudi Arabian University toward American and British accents by (1) seeing how they rate male and female speakers with each accent on various traits, such as confidence and friendliness, (2) testing their ability to identify each accent, and (3) asking directly which accent they prefer to model 


\section{CHAPTER 2: LITERATURE REVIEW}

\section{The Matched Guise Technique and Verbal Guise}

Technique

Since the advent of the Matched Guise Technique (MGT; Lambert, Hodgson, Gardner, \& Fillenbaum, 1960), language attitudes - defined as "speaker-internal psychological tendencies which are expressed by evaluating particular entities (e.g. a dialect or an ethnic group) with a degree of favor or disfavor" (Eagly \& Chaiken, 1993, p. 1) - have been the topic of countless studies. Lambert et al.'s original (1960) study focused on English and French speakers in Quebec, Canada. To minimize the effects of voice and message, and thereby isolate listeners' attitudes toward speakers of the languages in question, perfect French-English bilinguals were recorded reading the same neutral passage in each language. English- and French-speaking subjects then rated each of the English and French guises on a variety of traits, believing all had come from different speakers. Both English-speaking and French-speaking subjects rated the English-speaking guises significantly more favorably in terms of appearance, intelligence, dependability, ambition, and character. However, each language group rated its own language guises significantly more favorably in terms of kindness.

In addition to being used to compare attitudes toward different languages, such as French and English in Quebec (Genesee \& Holobow, 1989; Lambert et al., 1960; Lambert, Frankel, \& Tucker, 1966) and Hebrew and Arabic in the Middle East (Lambert, Anisfeld, \& YeniKomshian, 1965), the matched guise technique has been used to compare attitudes toward standard versus non-standard varieties of the 
same language, including African American English (Hensley, 1972; Johnson \& Buttny, 1982) and Chicano English (Arthur, Farrar, \& Bradford, 1974; Bouchard-Ryan \& Carranza, 1975; Bouchard-Ryan, Carranza, \& Moffie, 1977).

Despite its power, a significant limitation of the MGT is the need to find perfectly bilingual or bidialectal speakers who can produce the stimuli, since such speakers may be difficult or even impossible to find for certain pairs of languages and dialects. This limitation prompted the subsequent development of the Verbal Guise Technique (VGT; Cooper \& Fishman, 1974), which is identical to the MGT except that all of the stimulus recordings come from different speakers. Both the MGT and VGT are indirect methods of measuring participants' attitudes toward different groups, and are highly useful insofar as they "can reveal prejudices that might not - or, indeed, cannot - be expressed in other contexts" (McKenzie, 2008, p. 65).

\section{Language Attitudes of Non-Native Speakers}

There is relatively little research on non-native speakers' perceptions of different native accents/dialects. Chiba, Matsuura, and Yamamoto (1995) examined 169 Japanese EFL students' perceptions of various native and non-native accents of English, including those of two American speakers and one British speaker. The Japanese listeners rated native speakers more favorably than non-native speakers, but their ratings of American speakers vs. British speakers were not significantly different. Moreover, although listeners were able to identify native vs. 
non-native speakers, they could not reliably distinguish American vs. British speakers.

McKenzie (2008) examined the language attitudes of 558 Japanese college students toward English speakers with six different accents vernacular Glaswegian, Standard Glaswegian, Southern U.S. (Alabama), Midwestern U.S. (Ohio), and two advanced L2 speakers with Japanese L1, one with a "heavy" Japanese accent and the other with a "moderate" Japanese accent. In terms of competence (a cover term for what are also called status traits: intelligent, confident, fluent, and clear), the two American speakers were perceived the most favorably, followed by the two Glaswegian speakers, with the two Japanese-accented speakers evaluated the least favorably. In terms of social attractiveness (a cover term for what are also called solidarity traits: gentle, pleasant, funny, and modest), the heavily accented Japanese speaker was perceived the most favorably, followed by the vernacular Glaswegian and Southern U.S. speakers (in a statistical tie for second) and then the moderately accented Japanese speaker, with the Standard Glaswegian and Midwestern U.S. speakers in a statistical tie for last place. In other words, the Japanese listeners perceived native English speakers as more competent than non-native speakers and Americans as more competent than Britons. However, the listeners perceived Japanese-accented speakers and native English speakers with less standard accents as more socially attractive than native speakers with more standard accents.

The very limited research on language attitudes of non-native speakers makes it hard to know what to expect in the present study. 
Research challenging the so-called inherent value hypothesis has shown that listeners who are unfamiliar with a particular language (such as French or Greek) cannot tell which of two dialects of that language is considered 'better' by native speakers (see, e.g., Giles $\&$ Niedzielski, 1998). This may explain why the Japanese L1 participants in Chiba et al. (1995), who could not reliably distinguish American vs. British speakers, did not give significantly different ratings to American vs. British speakers. However, another group of Japanese L1 participants (in McKenzie, 2008) did give significantly different ratings to American vs. British speakers. Uncertainty remains, though, since McKenzie (2008) does not report testing whether the participants could accurately label the speakers as American or British.

The initial hypothesis is that Saudi students will rate the American and British speakers differently. It remain unclear, however, whether they will be able to distinguish American and British speakers consciously, and it is likewise unknown whether the ability to distinguish accents consciously is a necessary precondition for giving them different ratings. 


\section{CHAPTER 3: METHODOLOGY}

As is typical in Matched Guise and Verbal Guise research, testing this hypothesis will require a set of two studies using the same British and American stimulus recordings - the first to identify a set of relevant traits for the rating scales and the second to gather actual ratings on those scales. One could, of course, use a set of status and solidarity traits from another study or, indeed, from one's own imagination. Deriving the traits by eliciting descriptions from the target population, however, arguably makes the rating scales more relevant to that population and increases the validity and meaningfulness of the results.

\section{Preliminary Study - Method}

\section{$\underline{\text { Participants }}$}

Participants in the preliminary study were 30 Saudi females between the ages of 21 and 22 who were students in the English department at Northern Border University in Saudi Arabia.

\section{$\underline{\text { Materials }}$}

Consistent with the Verbal Guise Technique (VGT; Cooper \& Fishman, 1974), all of the stimulus recordings were produced by different speakers - 6 native speakers of American English (3 male, 3 female) and 6 native speakers of British English ( 3 male, 3 female), ranging in age from 20 to 50 . Note that no specific British or American dialect was targeted in this study, and the speakers who produced the stimuli were not asked about their dialects; the goal was simply to 
determine whether EFL students are able to distinguish or make judgments based on broadly different accents.

The speakers were not informed of the purpose of the study, but were simply asked to read a passage, entitled 'First people in Europe,' taken from a website for teaching ESL students called 'History in Levels' (see Appendix A). This passage was chosen for its neutral content that is easy enough for non-native English speakers to understand. Each speaker was recorded using the Voice Record App. Speakers were asked to read the passage twice; the first reading was for practice and the second was actually used in the study. The recordings were subsequently edited, using Audacity, to remove hesitations and in some cases to increase or decrease the speech rate so that all 12 recordings were as similar as possible in terms of fluency.

\section{$\underline{\text { Procedure }}$}

The preliminary study was administered by a university supervisor in a classroom setting. Participants were told that they would hear 12 native English speakers all reading the same passage and were asked to write down their impressions of each speaker's personal, social, economic, and vocational traits. Each participant was given a sheet of paper with the passage that the speakers would be heard reading (see Appendix A) and blank spaces in which to write their impressions. The 12 recordings were then played for the students in random order. Following each recording, the students were given three minutes to write down their impressions. Once all 12 recordings had been presented, the 
participants were thanked for participating in the study and the papers were collected.

\section{Preliminary Study - Results}

Participants suggested different features for the British and American speakers. Ninety percent of participants described one or more of the male and female British speakers as wealthy, formal, educated, arrogant, ambitious, confident, and attractive, and $60 \%$ of participants guessed they were news reporters or broadcasters. By contrast, only $20 \%$ of participants described one or more of the British speakers as poor, disorganized, and pessimistic. On the other hand, $40 \%$ of participants described the female American speakers as humble, thin, disorganized, and careless, and 30\% guessed they were housekeepers or teachers. However, $90 \%$ of participants described one or more of the male American speakers as unattractive, poor, old, and blond, while only $30 \%$ described one or more as young, tall, and humble.

Based on these results, the following traits were identified for use as rating-scale endpoints in the main study: attractive, confident, wealthy, educated, polite, humble, courteous, and friendly. Note that the first four are status traits and the latter four are solidarity traits.

\section{$\underline{\text { Main Study - Method }}$}

\section{$\underline{\text { Participants }}$}

Participants in the main study were 63 Saudi females, born and raised in Saudi Arabia, between the ages of 19 and 22 who were students in the English department at Northern Border University in Saudi 
Arabia, none of whom participated in the preliminary study. Data from another 132 participants were excluded because they failed to complete the rating task. The students' English instructors were all female nonnative speakers from Saudi Arabia, Egypt, Pakistan, India, and Jordan.

\section{$\underline{\text { Materials }}$}

The stimuli were the same 12 recordings of male and female British and American speakers that were used in the preliminary study.

\section{Procedure}

The main study was administered by the students' English teachers in a classroom setting. Participants were first given the rating sheet, which included instructions, the passage that the speakers would be heard reading, the 12 sets of rating scales, and a space for participants to indicate whether they thought each speaker was British or American. The instructions said, "As you listen to the speaker, please try to form an impression of them in your mind. Then, indicate where you would put them on each of the scales below, and also try to guess their English accents." The rating scales were 6-point, partially anchored Likert scales (see, e.g., Davies, 2008), whose endpoint labels consisted of the 8 traits that were selected based on the preliminary study and the negative forms of those traits (e.g., attractive - not attractive; see Appendix B). A 6-point scale is within Cox's (1980) optimal range of 5 to 9 points and lacks a middle point, which respondents tend to overuse (Cox, 1980).

Upon being given the questionnaire, participants were first thanked for choosing to participate and then told that they would be 
hearing 12 recordings of native English speakers all reading the same passage and would be asked to rate each speaker on a certain set of traits. After each recording was played, participants were given 2 minutes to rate the speaker before the next recording was played. After all 12 recordings had been played and rated, participants were asked to indicate and write on the sheet their favorite accent (British or American) and how long they had studied English. No other favorite-accent options were officially available, making it a sort of forced-choice question, though one student did write "both." Lastly, each of the 12 recordings was played again, in the same order, and participants were asked to identify each speaker's accent as either British or American. During this task, participants were given 30 seconds after each recording was played. After completing the questionnaire, the students were thanked for participating in the study and the forms were collected.

To address the possibility of order effects, the 12 recordings were presented in a different order in each of the four classes. Moreover, the left and right rating scale endpoints were reversed on half of the rating forms.

\section{Main Study - Results}

Of the 63 participants who completed the rating task, only 37 completed the task of identifying the speakers' accents and indicated how long they had been studying English, and only 33 of those 37 indicated which accent - British or American - they preferred. The 37 participants who completed the accent identification task did so with an average accuracy of 52.93\% (SD 21.63; range $16.67 \%-91.67 \%$ ), which a 
$t$-test revealed to be statistically no better than chance. The same 37 participants reported having studied English for an average of 8.24 years (SD 3.33; range $1-14$ years). Of the 33 who indicated a preferred accent, 16 reported preferring British, 16 American, and one said "both." Bivariate (Pearson) correlation analyses of the above data revealed no statistically significant relationship among participants' accuracy in identifying the speakers' accents, their years of study, and their preferred accent. Moreover, multiple regression analyses showed no statistically significant interaction between participants' accuracy in identifying the speakers' accents, their years of study, or their preferred accent and their ratings of the 12 speakers. These findings suggest that the accent identification, years of study, and preferred accent data are unimportant, so the scale-rating data from all 63 participants who completed the rating task were analyzed together.

As is customary in verbal guise research, each of the eight rating scales was treated as a separate dependent variable for the purposes of analysis. Consequently, eight 2 (gender: male, female) $\times 2$ (nationality: American, British) ANOVAs were conducted. These ANOVAs revealed a significant main effect of gender on five of the eight traits - all in favor of the female speakers. Specifically, the female speakers were rated significantly more attractive, confident, educated, polite, and friendly. The analyses also revealed significant main effects of nationality on five traits - all in favor of the British speakers, who were rated significantly more attractive, confident, wealthy, educated, and friendly. There were also two sets of ratings that showed statistically significant interactions between gender and nationality, namely, confident and wealthy. These 
interactions are driven by the relatively more favorable ratings given the female British speakers. Table 1 shows the statistically significant $p$ values, and Figures 1 through 7 show the significant differences graphically.

Table 1

Summary of Statistical Significant p-Values

\begin{tabular}{lccc}
\hline Trait & $\begin{array}{c}\text { Main Effect of } \\
\text { Gender }\end{array}$ & $\begin{array}{c}\text { Main Effect of } \\
\text { Nationality }\end{array}$ & Interaction \\
\hline Attractive & $.001^{*}$ & $.001^{*}$ & \\
Confident & .007 & .010 & .004 \\
Wealthy & & .037 & .007 \\
Educated & $.001^{*}$ & $.005^{*}$ & \\
Polite & .012 & & \\
Humble & & & \\
Courteous & & & \\
Friendly & $.002^{*}$ & .007 & \\
\hline
\end{tabular}

*Statistically significant even if the Bonferroni correction for multiple comparisons is applied, thus moving the alpha-level from .05 to .006. 


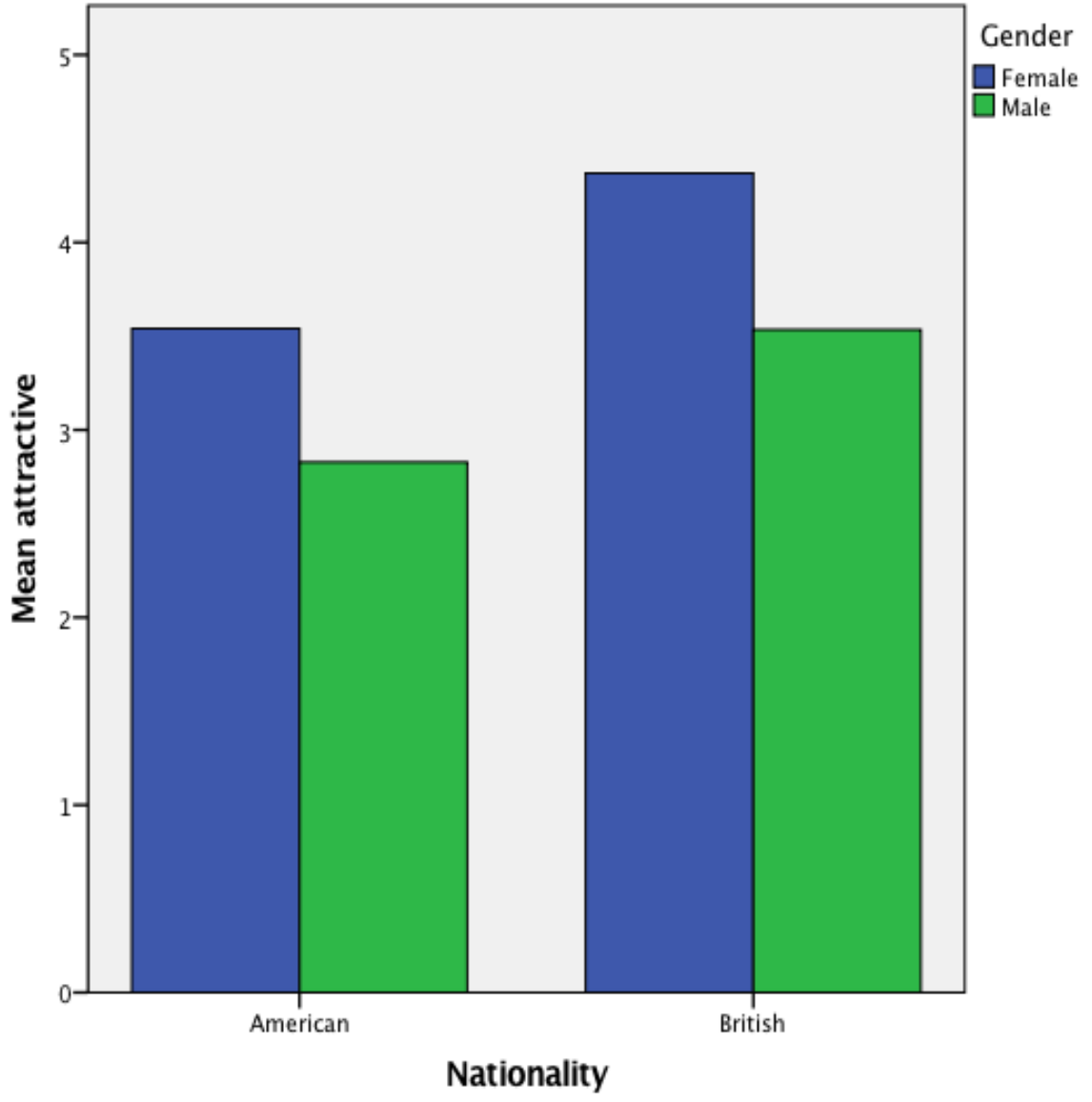

Figure 1. Mean attractive

Visualization of participants' ratings of speaker attractiveness, showing the significant main effects of gender (female > male) and nationality (British > American). 


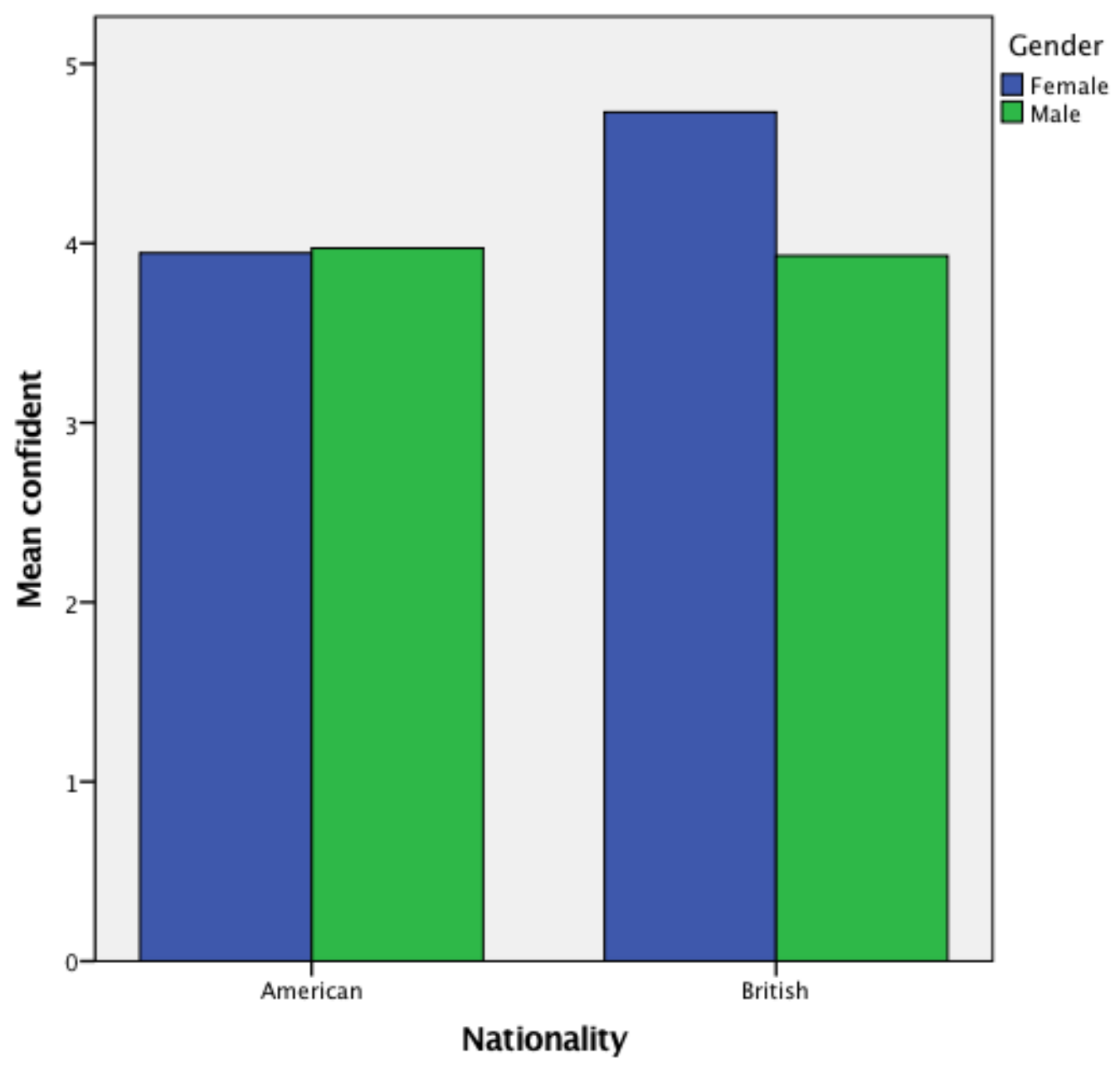

Figure 2. Mean confident

Visualization of participants' ratings of speaker confidence showing the significant main effects of gender (female > male) and nationality (British > American), as well as the significant interaction between gender and nationality. Note that all three effects appear to be driven by the high ratings of the female British speakers. 


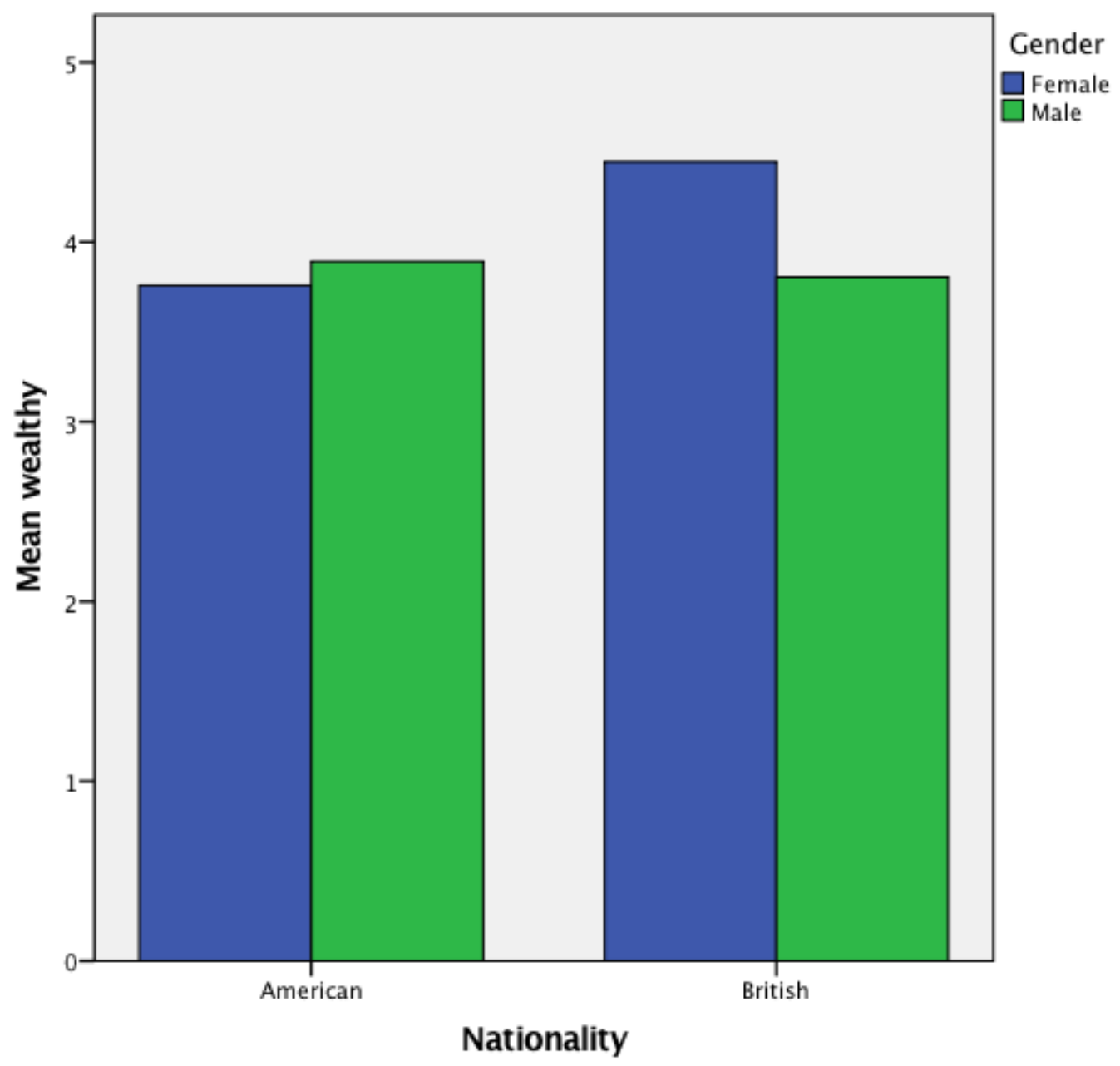

Figure 3. Mean wealthy

Visualization of participants' ratings of speaker wealthiness, showing the significant main effect of nationality (British > American), as well as the significant interaction between gender and nationality. Again, both effects appear to be driven by the high ratings of the female British speakers. 


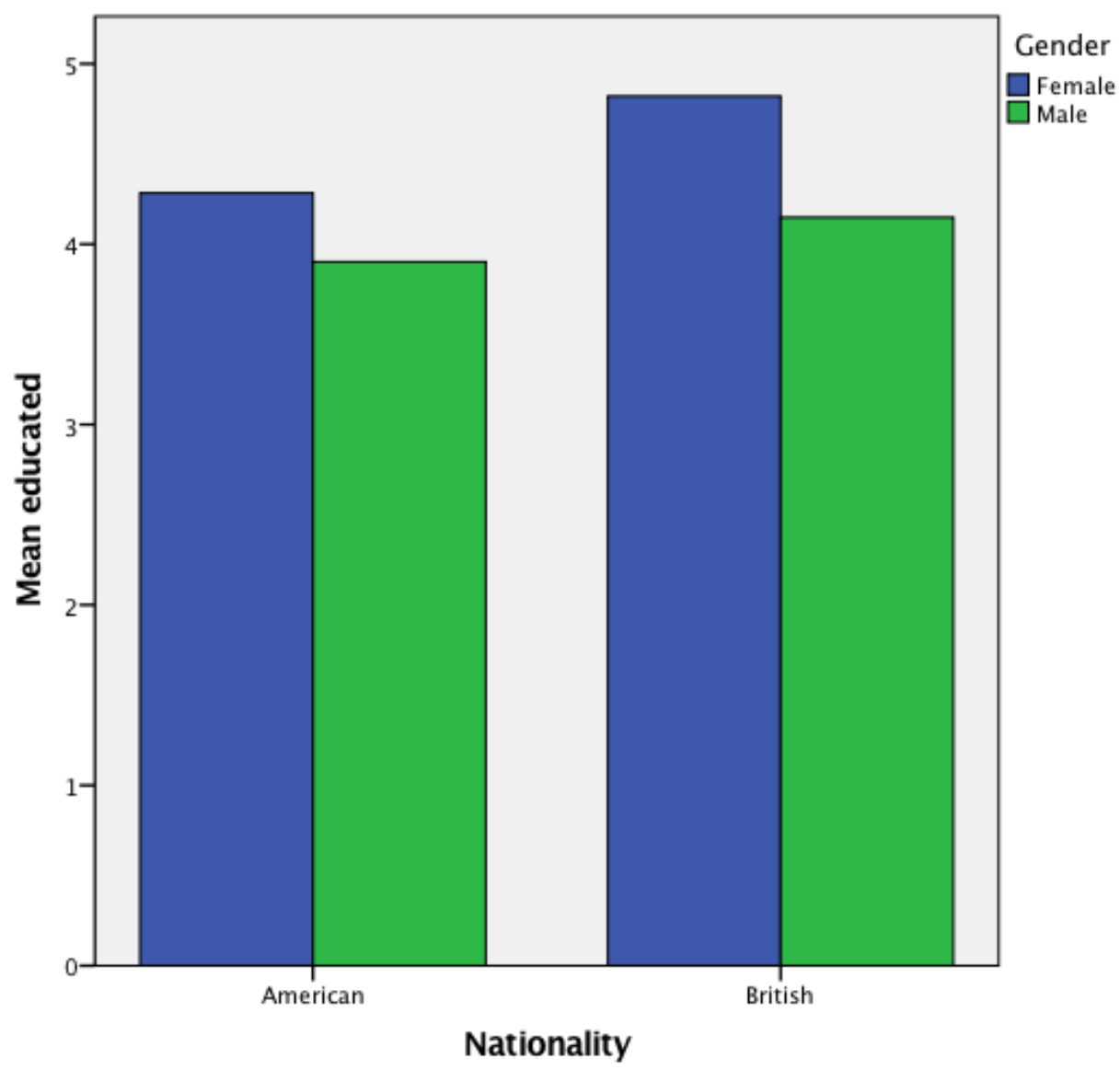

Figure 4. Mean educated

Visualization of participants' ratings of speaker educatedness, showing the significant main effects of gender (female $>$ male) and nationality (British $>$ American). 


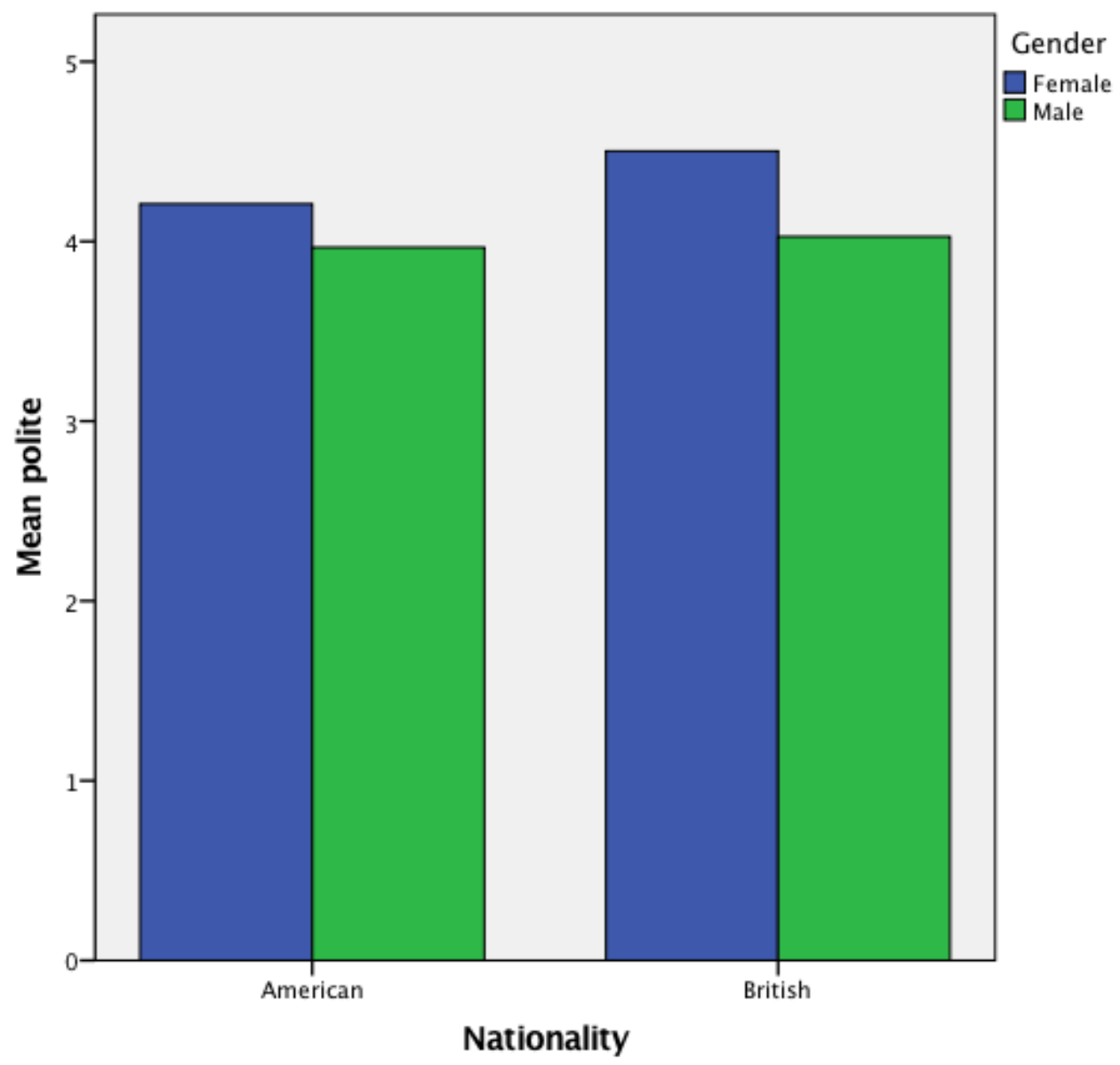

Figure 5. Mean polite

Visualization of participants' ratings of speaker politeness, showing the significant main effect of gender (female > male). The mean gender difference is larger for the British speakers than the American speakers, but both go in the same direction - favoring female speakers. 


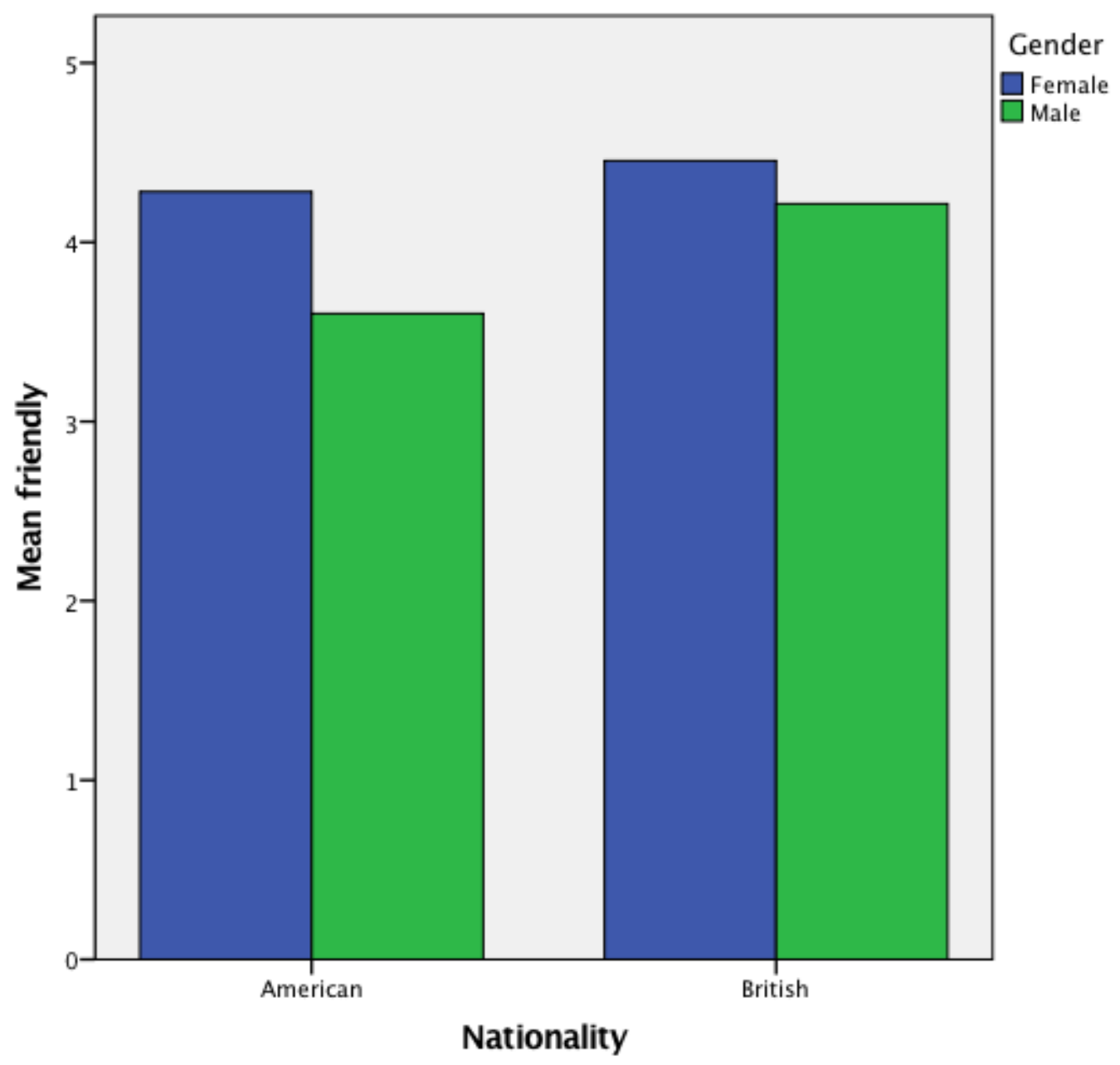

Figure 6. Mean friendly

Visualization of participants' ratings of speaker friendliness, showing the significant main effects of gender (female > male) and nationality (British > American). It seems that American males are driving the effects here. 


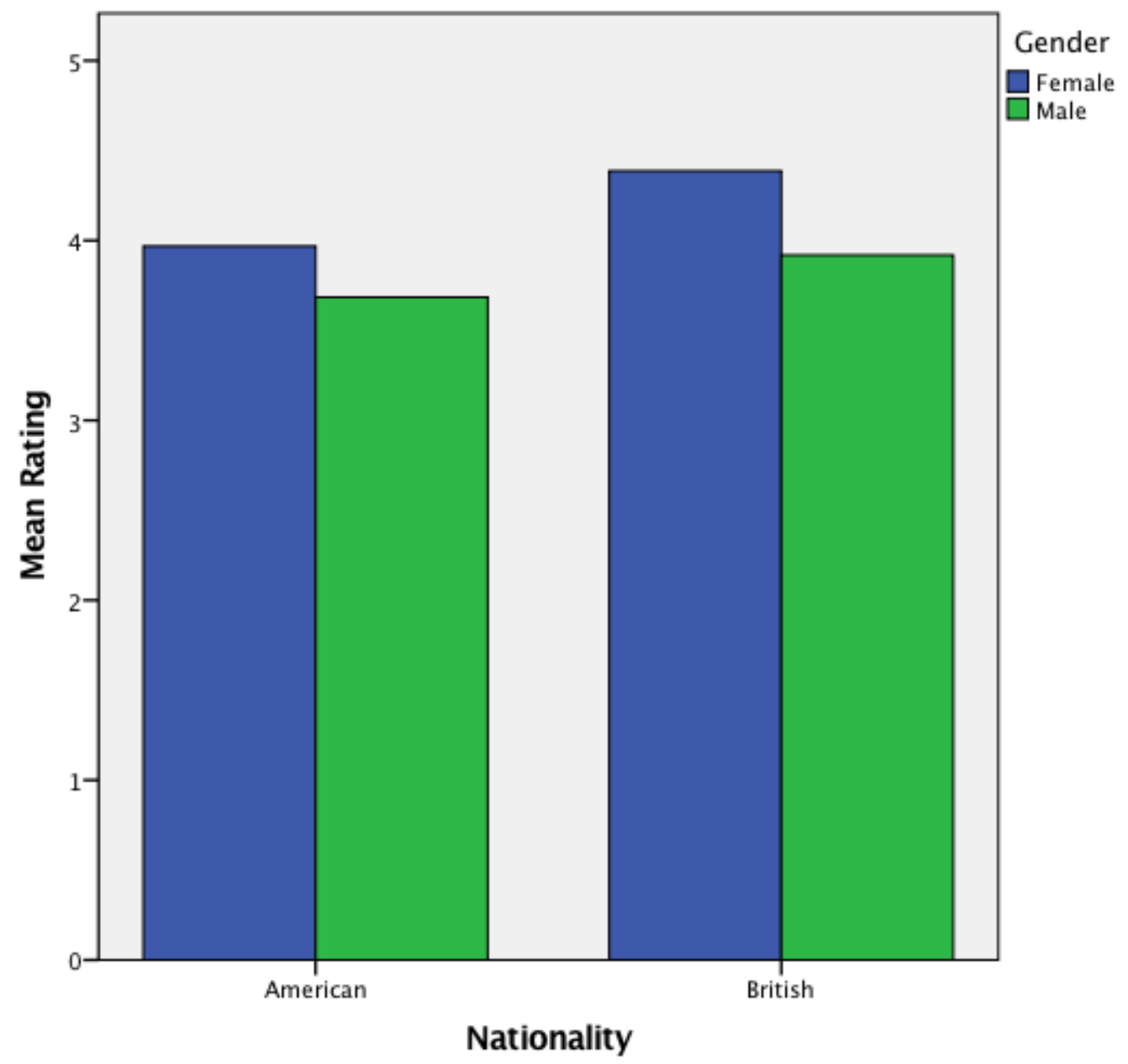

Figure 7. Mean rating

Visualization of participants' ratings of the speakers based on all eight rating scales averaged together, showing significant main effects of gender (female > male) and nationality (British > American). 


\section{CHAPTER 4: DISCUSSION}

Despite participants' inability to distinguish British and American accents, which parallels Chiba et al.'s (1995) findings for Japanese, the results show that participants perceived the British speakers significantly more favorably than the American speakers on a variety of traits and did not favor the American speakers on any. This strict uniformity in the direction of the effect seems unlikely to be a coincidence, and suggests that conscious ability to distinguish speakers' dialects and identify their nationalities is not a necessary precondition to having different (unconscious) perceptions of those speakers. The bases of the unconscious perceptions found in this study remain a mystery.

Also striking is the difference between the status traits (attractive, confident, wealthy, educated; the top four in Table 1) and the solidarity traits (polite, humble, courteous, and friendly; the bottom four in Table 1). In particular, participants' ratings on all four status scales show significant main effects of nationality, and all but one (wealthy) show significant main effects of gender. Of the four solidarity scales, on the other hand, only one (polite) shows a significant main effect of nationality, and only two (polite and friendly) show significant main effects of gender. This suggests that whatever difference these Saudi listeners unconsciously perceived between American and British speakers had much more to do with status than solidarity. 


\section{CHAPTER 5: LIMITATIONS AND CONCLUSION}

\section{$\underline{\text { Limitations }}$}

Perhaps the biggest limitation of the present study is the inclusion of only female participants. Another study would be needed to explore male perceptions of male and female British and American speakers. The other major limitation is that the researcher was in the U.S. during data collection and, thus, could not oversee the procedure. As a result, some of those collecting the data did not follow the procedure, and many participants' data could not be used.

\section{$\underline{\text { Conclusions }}$}

Despite their inability to distinguish British and American accents, the Saudi female EFL students studied showed a significant preference for British speakers over American speakers and female speakers over male speakers, particularly in terms of the speakers' status. This suggests that conscious ability to distinguish speakers' dialects and identify their nationalities is not a necessary precondition to having different (unconscious) perceptions of those speakers. 


\section{REFERENCES}




\section{REFERENCES}

Arthur, B., Farrar, D., \& Bradford, G. (1974). Evaluation reactions of college students to dialect differences in the English of MexicanAmericans. Language and Speech, 17(2), 255-270.

Bouchard-Ryan, E., \& Carranza, M. A. (1975). Evaluative reactions of adolescents toward speakers of Standard English and Mexican American accented English. Journal of Personality and Social Psychology, 31(5), 855-863.

Bouchard-Ryan, E., Carranza, M. A., \& Moffie, R. W. (1977). Reactions toward varying degrees of accentedness in the speech of SpanishEnglish bilinguals. Language and Speech, 20(3), 267-273.

Chiba, R., Matsuura, H., \& Yamamoto, A. (1995). Japanese attitudes toward English accents. World Englishes, 14(1), 77-86.

Cooper, R. L., \& Fishman, J. A. (1974). The study of language attitudes. International Journal of the Sociology of Language, 3, 5-19

Cox, E. P. (1980). The optimal number of response alternatives for a scale: A review. Journal of Marketing Research, 17(4), 407-422.

Davies, R. S. (2008). Designing a response scale to improve average group response reliability. Evaluation \& Research in Education, 21(2), 134-146.

Eagly, A. H., \& Chaiken, S. (1993). The psychology of attitudes. Orlando, FL: Harcourt Brace Jovanovich.

Genesee, F., \& Holobow, N. E. (1989). Change and stability in intergroup perceptions. Journal of Language and Social Psychology, 8(1), 17-38.

Giles, H. \& Niedzielski, N. (1998). Italian is beautiful, German is ugly. In L. Bauer \& P. Trudgill (Eds.), Language myths (pp. 85-93). New York, NY: Penguin.

Hensley, A. (1972). Black high school students' reactions to Black speakers of Standard and Black English. Language Learning, 22(2), 253-259.

Johnson, F. L., \& Buttny, R. (1982). White listeners' responses to "sounding Black" and "sounding White": The effect of message content on judgments about language. Communication Monographs, 49(1), 33-49. 
Lambert, W. E., Anisfeld, M., \& Yeni-Komshian, G. (1965). Evaluational reactions of Jewish and Arab adolescents to dialect and language variations. Journal of Personality and Social Psychology, 2(1), 84-90.

Lambert, W. E., Frankel, H., \& Tucker, G. R. (1966). Judging personality through speech: A French-Canadian example. Journal of Communication, 16(4), 305-321.

Lambert, W. E., Hodgson, R. C., Gardner, R. C., \& Fillenbaum, S. (1960). Evaluational reactions to spoken language. Journal of Abnormal and Social Psychology, 60(1), 44-51.

McKenzie, R. M. (2008). Social factors and non-native attitudes towards varieties of spoken English: a Japanese case study. International Journal of Applied Linguistics, 18(1), 63-88. 
APPENDICES 
APPENDIX A: TEXT OF THE PASSAGE READ BY SPEAKERS 
The oldest human footprints outside of Africa have been discovered in Britain, dating back around a million years. They were found on a beach on the Norfolk coast and are direct evidence of the earliest known humans in Northern Europe. 
APPENDIX B: RATING SCALE 


\begin{tabular}{|l|l|l|l|l|l|l|l|}
\hline & 1 & 2 & 3 & 4 & 5 & 6 & \\
\hline Confident & & & & & & & Not confident \\
\hline Not Attractive & & & & & & & Attractive \\
\hline Wealth & & & & & & & Not wealth \\
\hline Not educated & & & & & & & Educated \\
\hline Humble & & & & & & & Not humble \\
\hline Not polite & & & & & & & Polite \\
\hline Friendly & & & & & & & Not friendly \\
\hline Not courteous & & & & & & & Courteous \\
\hline
\end{tabular}




\section{Fresno State}

\section{Non-Exclusive Distribution License}

(to archive your thesis/dissertation electronically via the library's eCollections database)

By submitting this license, you (the author or copyright holder) grant to Fresno State Digital Scholar the non-exclusive right to reproduce, translate (as defined in the next paragraph), and/or distribute your submission (including the abstract) worldwide in print and electronic format and in any medium, including but not limited to audio or video.

You agree that Fresno State may, without changing the content, translate the submission to any medium or format for the purpose of preservation.

You also agree that the submission is your original work, and that you have the right to grant the rights contained in this license. You also represent that your submission does not, to the best of your knowledge, infringe upon anyone's copyright.

If the submission reproduces material for which you do not hold copyright and that would not be considered fair use outside the copyright law, you represent that you have obtained the unrestricted permission of the copyright owner to grant Fresno State the rights required by this license, and that such third-party material is clearly identified and acknowledged within the text or content of the submission.

If the submission is based upon work that has been sponsored or supported by an agency or organization other than Fresno State, you represent that you have fulfilled any right of review or other obligations required by such contract or agreement.

Fresno State will clearly identify your name as the author or owner of the submission and will not make any alteration, other than as allowed by this license, to your submission. By typing your name and date in the fields below, you indicate your agreement to the terms of this distribution license.

\section{Embargo options (fill box with an X).}

\section{$\mathrm{x}$ Make my thesis or dissertation available to eCollections immediately upon submission.}

Embargo my thesis or dissertation for a period of 2 years from date of graduation.

Embargo my thesis or dissertation for a period of 5 years from date of graduation.

\section{Eiman Alenezy}

Type full name as it appears on submission

$$
\text { November 16, } 2015
$$

Date 